\title{
Mapping the Research Trends of Household Waste Recycling: A Bibliometric Analysis
}

\author{
Kun Shi, Yi Zhou and Zhen Zhang * \\ Department of Environmental Science \& Engineering, Fudan University, Shanghai 200433, China; \\ 18210740035@fudan.edu.cn (K.S.); 18210740074@fudan.edu.cn (Y.Z.) \\ * Correspondence: zhenzhang@fudan.edu.cn
}

Citation: Shi, K.; Zhou, Y.; Zhang, Z. Mapping the Research Trends of Household Waste Recycling: A Bibliometric Analysis. Sustainability 2021, 13, 6029. https://doi.org/ $10.3390 /$ su13116029

Academic Editor: Christian N. Madu

Received: 12 May 2021

Accepted: 26 May 2021

Published: 27 May 2021

Publisher's Note: MDPI stays neutral with regard to jurisdictional claims in published maps and institutional affiliations.

Copyright: (c) 2021 by the authors. Licensee MDPI, Basel, Switzerland. This article is an open access article distributed under the terms and conditions of the Creative Commons Attribution (CC BY) license (https:// creativecommons.org/licenses/by/ $4.0 /)$.

\begin{abstract}
Household waste recycling has been widely considered the key to reducing the pollution caused by municipal solid waste and promoting sustainable development. This article aims to clarify the status and map the research trends in the field of household waste recycling. Bibliometric analysis is performed using bibliometrix based on publications during 1991-2020 in the Web of Science database. Results show that academic output in this field is growing rapidly. The top contributing authors, countries, institutions, and journals are identified. Collaboration network of authors, institutions, and countries are created and visualized. The most influential and cited articles in this field mainly focus on factors influencing residents' recycling behavior from the perspectives of sociopsychology and economics. The theory of planned behavior is the most widely used psychological model. Other research hotspots include electronic waste, source separation, life cycle assessment, sustainability, organic waste, and circular economy. Studies on household waste recycling have become more and more comprehensive and interdisciplinary with the evolution of research themes.
\end{abstract}

Keywords: bibliometric analysis; bibliometrix; household recycling; research trends; science mapping; waste management

\section{Introduction}

Currently, municipal solid waste management has become one of the most critical environmental issues in the world [1]. Environmental pollution caused by municipal solid waste has led to health threats to residents [2]. With the continuous growth of world's population and the improvement of industrialization and urbanization, the problem of waste management is expected to become more serious in the future [3]. The continuous increase in the amount of municipal solid waste restricts the improvement of residents' quality of life and has become an important obstacle to sustainable development [4].

Municipal solid waste includes but is not limited to household waste, industrial waste, commercial waste, construction and demolition waste, and waste generated from schools, hospitals, and road sweeping [5]. The majority of municipal solid waste is contributed to by household waste [6]. Compared with other sources of waste, the composition of household waste is more complex [7], which results in greater challenges for urban management. In this context, promoting the recycling of household waste is critical to reduce the volumes of waste generated, conserve natural resources, and move towards a circular economy [8].

Given that household waste recycling has become an area of increasing concern, and related recycling schemes have been put into practice in many countries [9-13], the amount of academic research on certain topics has increased significantly in recent years. These studies focus on various aspects such as environmental science and technology, sociology, psychology, and economics. Specifically, the majority of the studies focus on factors influencing residents' attitudes toward recycling and determinants of their recycling behavior, as the success of household waste recycling programs depends on residents' consistently positive participation and their support for recycling policies [14]. Psychological 
factors including social norms [15], moral norms [16], environmental concern [17], recycling habits [18], and past experience [19] have been examined and proven to have significant influence on individual's recycling behavior and willingness to recycle. Other studies have emphasized the importance of objective situational factors such as the convenience of recycling [20] and laws and regulations [21,22]. From an economic perspective, people tend not to participate in recycling when the expected utility of recycling is not enough to cover the cost [8]. Hence, the introduction of financial incentives could be an effective driver for promoting recycling programs [23].

However, with the rapid increase in the number of academic publications year by year, it is becoming increasingly difficult to keep up with the all the latest studies. Voluminous and fragmented research streams hamper the accumulation of knowledge and empirical evidences from previous research papers. In this case, researchers would spend excessive time and effort when reviewing the literature, and they may still not be able to get a full picture of a certain research field. Therefore, bibliometric methods have been developed for structured analysis of large amounts of literature information and identification of the research trends of an area based on the statistical measurement of scientific productions [24]. Several studies have already applied bibliometric analysis to the field of waste management. $\mathrm{Li}$ et al. (2018) [25] analyzed the research trends on solid waste reuse and recycling from 1992 to 2016. Some researchers focused on specific types of municipal solid waste, such as construction and demolition waste [26,27] and electronic waste [28,29]. Tsai et al. (2020) [30] performed bibliometric analysis on municipal solid waste management in the context of the circular economy. Wang et al. (2020) [31] combined bibliometrics with text-mining and reviewed the evolution of municipal waste management. According to these existing bibliometric studies, recycling is one of the key issues of waste management. Furthermore, Tsai et al. [30] emphasized that the promotion and enhancement of household waste recycling programs is a future challenge and direction, so it is essential to understand personal recycling behaviors. Meanwhile, there is still lack of bibliometric studies focusing on household waste recycling, as no such publications have been found.

The present study aims to map the research trends of household waste recycling based on bibliometric approaches. Specifically, the objectives of this article are to answer the following questions:

1. Which authors, journals, institutions, and countries have contributed the most to this field of research?

2. How do the authors, institutions, and countries relate to and cooperate with each other in academic research?

3. What are the most influential articles that are worth attention, and what are their arguments?

4. What are the research hotspots in this field, and how do they evolve over time?

By filling the gaps in bibliometric analysis in the field of household recycling, it is hoped that this article can provide a "big picture" of the field for future studies and help researchers find topics worth studying. In the next section, the data acquisition process and the methodology are explained in detail. Section 3 presents the results of the bibliometric analysis, including an overview of the scientific production, collaboration network analysis, citation analysis, and conceptual structure analysis. Section 4 presents the conclusions and prospects for future research.

\section{Materials and Methods}

\subsection{General Workflow}

This study adopts the standard workflow for science mapping concluded by Zupic and Cater [32], which comprises the following five stages: study design, data compilation, data analysis, data visualization, and interpretation. The purpose of this study is to map the research area of household waste recycling and gain insights into this area through bibliometric analysis. Therefore, certain keywords, such as "household waste recycling", were identified as the search terms, and the publication database was filtered using Web of 
Science. After finishing the data collection process, the bibliometric method was adopted to carry out a series of data analyses: general descriptive analysis, co-citation analysis, co-word analysis, collaborative network analysis, and thematic evolution analysis. Several scientific publication networks were established from the data and visualized for a better understanding of the research trends. Finally, the results were interpreted and discussed.

\subsection{Data Collection}

In this study, Clarivate Analytics Web of Science (WoS) was chosen as the source of bibliographic information, as it is one of the most widely utilized databases in scientometrics [33-35] and provides comprehensive and detailed literature data for download [33,36]. Data was obtained from the Science Citation Index Expanded (SCI-E) and the Social Sciences Citation Index (SSCI) databases with the search keywords "Household Waste Recycling". The timespan was limited to all years no later than 2020, and the inquiry was performed on 24 February 2021. Furthermore, the search results were limited to only English articles. As a result, a total of 1295 publications were finally returned, with the very first one published in 1991.

Data exported from the results queried through WoS consists of the following information: author(s), title, source, abstract, cited reference, addresses, times cited, keywords, and cited reference count. These contents were further used as the materials for the bibliometric analysis presented in detail in Section 3.

\subsection{Bibliometric Analysis}

Bibliometric analysis in this paper mainly entails descriptive analysis and network extraction. Descriptive analysis is used to investigate the evolution of scientific production and identify the most influential articles, authors, journals, and countries of the research area. Network extraction is further divided into different approaches: co-citation analysis, co-author analysis, co-word analysis, and bibliographic coupling analysis. These approaches help us map the social structure of the research community and the conceptual structure of the field.

The R package bibliometrix 3.0.3 developed by Aria and Curulo [24], and the software RStudio were used to perform bibliometric analysis and visualization of the results. At present, researchers have developed numerous tools for bibliometric analysis, the most commonly used ones being VOSviewer [37], SciMAT [38], BibExcel [39], CitNetExplorer [40], and CiteSpace [41]. However, many of these software do not support the complete standard workflow of science mapping [24]. Programmed in the open-source R language, the bibliometrix package cannot only meet all the needs of the whole-process bibliometric analysis but also integrate with other statistical $\mathrm{R}$ packages flexibly.

\section{Results and Discussion}

This section presents the results drawn from the bibliometric analysis and visualizes the related bibliographic networks.

The data collection contains 1295 published articles from 334 journals indexed by SCI-E and SSCI up to 2020, as well as 36,544 references cited by the articles. A total of 3362 authors contribute to the collected publications, of which most are multi-authored articles. The majority of the publications (1048 or $80.93 \%$ ) fall into the Web of Science categories of environmental sciences ( 872 or $67.34 \%$ ), engineering environmental (574 or $44.32 \%$ ), environmental studies (191 or $14.75 \%$ ), green sustainable science technology (183 or $14.13 \%$ ), and economics ( 89 or $6.87 \%$ ). In the top 5 WoS categories, 843 articles are multidisciplinary, accounting for $80.44 \%$ of the total number.

In the following subsections, we first present a descriptive analysis of scientific production by years, countries, authors, and journals. Some indices are also calculated as a supplement to measure the productivity and citation impact. Then, the social structure of the research area is mapped through collaboration analysis to show how authors, institutions, and countries relate to each other. The third part of this section focuses on the most 
influential research in the field, including (1) the most cited publications in the dataset; (2) the most cited references in the dataset, which refer to the publications cited the most by the articles in the data collection; (3) the most local cited publications, which refer to the publications in the data collection cited the most by other publications in the collection. The fourth part analyses the high-frequency keywords and major research themes to reveal the conceptual structure of the field. In addition, a Sankey diffluence diagram of different time slices is presented to help identify the evolution of research themes in the field of household waste recycling over time.

\subsection{Analysis of Scientific Production}

Figure 1 shows the trend in quantity of articles published between 1991 and 2020. The query performed as described in Section 2 returned no result before 1991 as the Web of Science Core Collection mainly started archiving in 1992 [36]. The number of publications followed a mild but continuous growth trend until around 2005, when a more rapid growth began. Starting from 2009, the number of scientific productions fluctuated for four years. A new round of rapid growth started again from 2014 until now. Over the past 30 years, the annual number of publications increased from 1 in 1991 to 141 in 2020, with an annual growth rate of $18.61 \%$. The general trend indicates that this field is still in the expansion period and receives increasing attention from research communities.

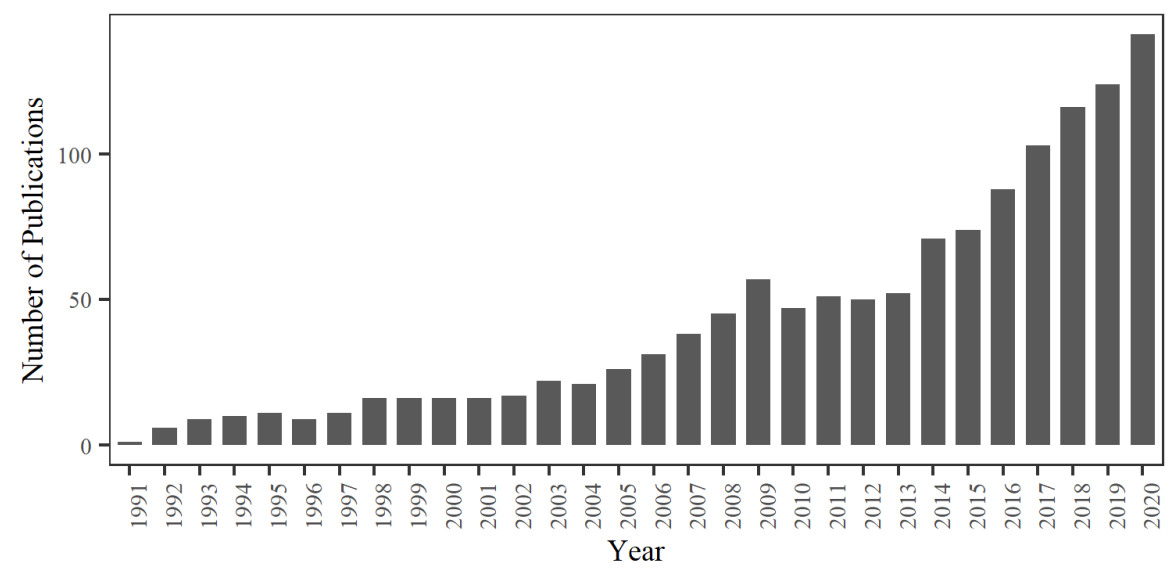

Figure 1. The annual number of publications about household waste recycling based on the data from SCIE and SSCI.

Figure 2 shows the 10 most productive countries and the number of publications by them. As the most populated county and facing serious waste management problems [42-44], China also produced the most publications of all the countries. The United States, who generated more municipal solid waste per year than any other countries [42,45], is the second most productive country regarding the number of publications. The United Kingdom is closely behind the United States. Japan ranks fourth but has the second highest number of multiple country publications. 


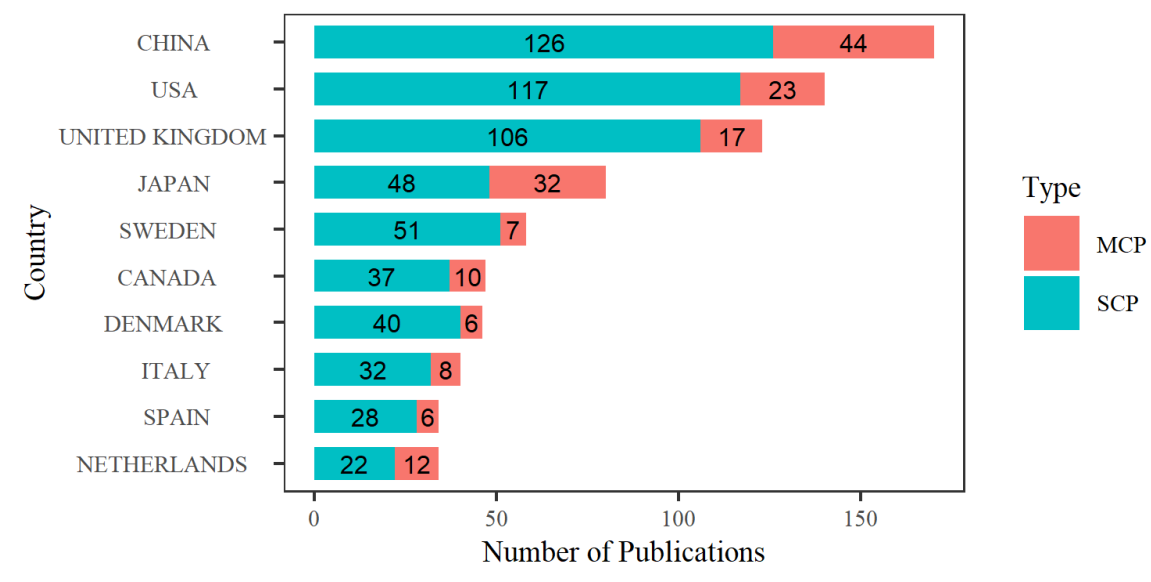

Figure 2. Number of publications in SCIE and SSCI about household waste recycling by country, grouped by multiple country publications $(\mathrm{MCP})$ and single country publications (SCP).

However, when taking into consideration the number of total citations, the United Kingdom and the United States have the highest number of total citations (5343 and 4146, respectively). Germany holds the first position in terms of the average article citations (58.94 citations per article). Although having produced the most publications, China has relatively lower average citations than most of the countries on the list. Table 1 lists the top 10 countries with the highest scientific production in household waste recycling.

Table 1. Top 10 countries ranked by total citations.

\begin{tabular}{cccc}
\hline Rank & Country & Total Citations & Average Article Citations \\
\hline 1 & United Kingdom & 5343 & 43.44 \\
2 & USA & 4146 & 29.61 \\
3 & China & 3353 & 19.72 \\
4 & Sweden & 1938 & 33.41 \\
5 & Germany & 1827 & 58.94 \\
6 & Italy & 1364 & 34.1 \\
7 & Japan & 1192 & 14.9 \\
8 & Denmark & 1143 & 24.85 \\
9 & Canada & 1110 & 23.62 \\
10 & Malaysia & 970 & 33.45 \\
\hline
\end{tabular}

The research field involved 3362 authors in total, among which 2876 authors have 1 article, 440 authors have $2-4$ articles, 37 authors have 5-7 articles, and 9 authors have more than 8 articles published.

Table 2 shows the main variables related to the most influential authors on the research topic. Ian Williams from the University of Southampton is the most productive author with 16 published articles (total articles in WoS: 102, overall h-index: 30), followed by Marie Harder with 13 publications (total articles in WoS: 64, overall h-index: 18), and Adam Read with 10 publications (total articles in WoS: 60, overall h-index: 19). The three authors leading the ranking are all affiliated with institutes in the United Kingdom. Four of the other authors on the list are from universities in China, while two are from the Technical University of Denmark. In addition, Ryan Woodard from the University of Brighton co-authored all his eight articles with Marie Harder. 
Table 2. Top 10 authors with the highest production of articles.

\begin{tabular}{|c|c|c|c|c|c|}
\hline Authors & Affiliation & h-Index & TC & $\mathbf{N}$ & PY \\
\hline Williams, I.D. & University of Southampton, UK & 12 & 562 & 16 & 2004 \\
\hline Harder, M.K. & $\begin{array}{l}\text { University of Brighton, UK } \\
\text { Fudan University, China }\end{array}$ & 10 & 240 & 13 & 2001 \\
\hline Read, A.D. & University of Northampton, UK & 10 & 790 & 10 & 1998 \\
\hline Wang, Y. & Nankai University, China & 5 & 177 & 9 & 2010 \\
\hline Astrup, T.F. & Technical University of Denmark, Denmark & 9 & 177 & 9 & 2014 \\
\hline Woodard, R. & University of Brighton, UK & 8 & 193 & 9 & 2001 \\
\hline Christensen, T.H. & Technical University of Denmark, Denmark & 6 & 236 & 8 & 2006 \\
\hline Wang, Z. & Beijing Institute of Technology, China & 8 & 285 & 8 & 2012 \\
\hline $\mathrm{Wu}, \mathrm{Y}$. & Beijing University of Technology, China & 7 & 173 & 8 & 2015 \\
\hline Chen, $\mathrm{H}$. & Jinan University, China & 4 & 74 & 7 & 2017 \\
\hline
\end{tabular}

TC: total citations; N: number of publications; PY: year of first publication.

Figure 3 describes the main authors' production over time in the field of household waste recycling. Shan Shan Chung from Hong Kong Baptist University published the first paper about a case study of recycling behavior and the attitude of Hong Kong people in 1994 [46], which is the earliest among the main influential authors. Ian Williams and Maire Harder, as the most productive authors, have started to publish papers in 2004 and 2001, respectively, and are still publishing new papers in recent years. Adam Read, who was active in the field between 1998 and 2008, has the highest number of total citations. Adam Read's paper Using the Theory of Planned Behaviour to Investigate the Determinants of Recycling Behaviour: a Case Study from Brixworth, UK, published in Resources, Conservation and Recycling journal, has been cited 364 times [47]. Another paper focusing on the implementation of a marketing communications strategy for curbside recycling, published in the same year, has also got 60 citations [48]. Beginning in the 2010s, scholars from China have become more and more influential in the aspect of scientific productions, including Yan Wang from Nankai University, Zhaohua Wang from Beijing Institute of Technology, Yufeng Wu from Beijing University of Technology, and Hui Chen from Jinan University.

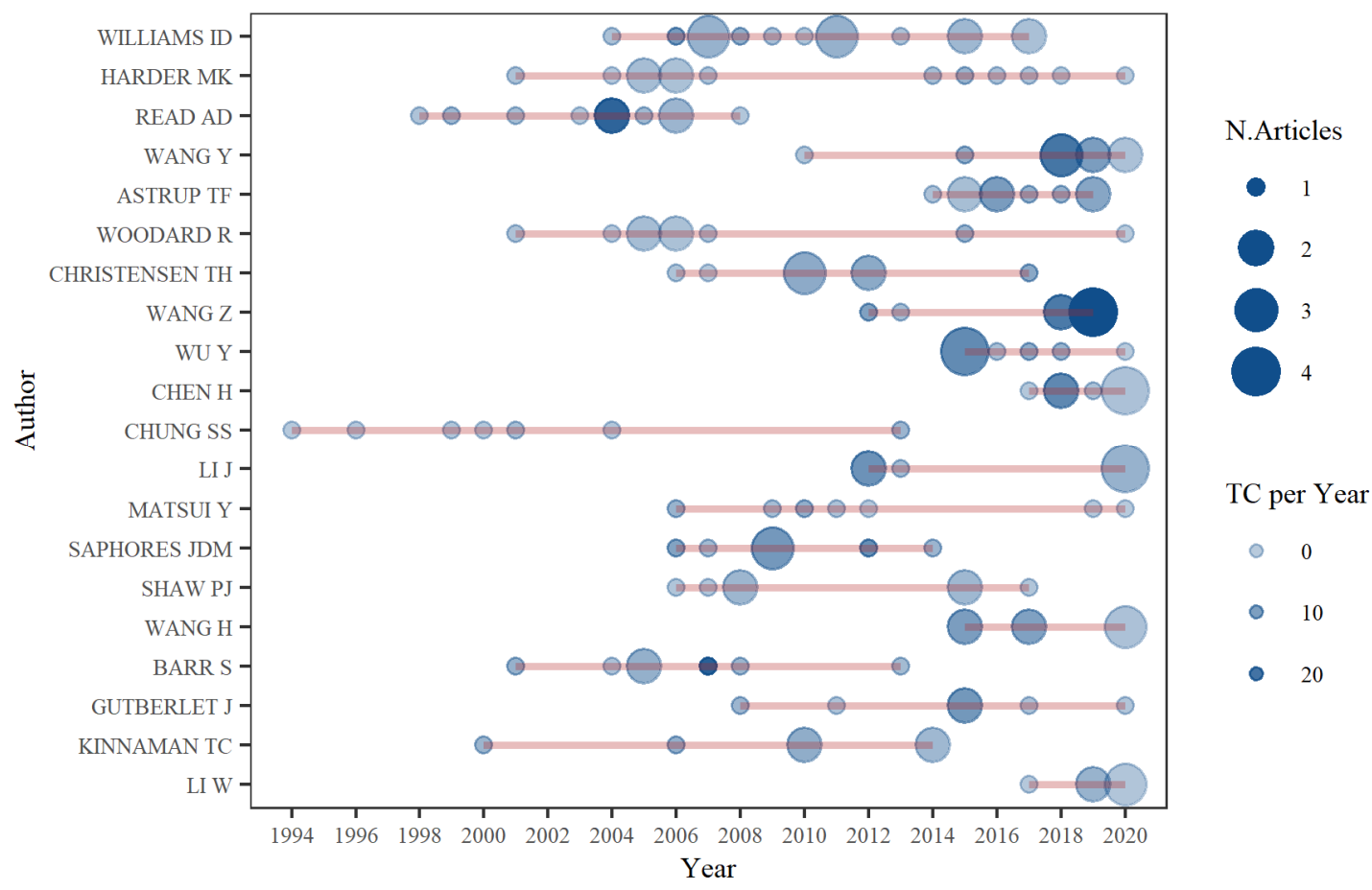

Figure 3. The top 20 authors' production over time. The size of the nodes represents the number of published articles (N.Articles), and the transparency represents the total citations (TC) per year. 
A total of 334 journals or other types of sources have published articles on the topic of our study. Of the sources, $69.5 \%$ have published only one article, and 16 journals have published 10 or more articles. The top 10 productive journals listed in Table 3 account for $53.2 \%$ of the total output. Resources, Conservation and Recycling ranks the first in both the number of articles (180) and total citations (6253), followed by Waste Management (159 articles and 4462 citations), Waste Management \& Research (85 articles and 1143 citations), and Journal of Cleaner Production (77 articles and 1831 citations). Resources, Conservation and Recycling also published the first article on household waste recycling in 1991 in our data collection. Besides the journals focusing on waste management, more comprehensive journals about environmental studies also appears on the top list, such as Journal of Cleaner Production, which also publishes articles about cleaner production, environmental, and sustainability research.

Table 3. Top 10 journals with the highest production of articles.

\begin{tabular}{lllll}
\hline Source & h-Index & TC & N & PY \\
\hline Resources, Conservation and Recycling & 42 & 6253 & 180 & 1991 \\
Waste Management & 38 & 4462 & 159 & 2003 \\
Waste Management \& Research & 18 & 1143 & 85 & 1994 \\
Journal of Cleaner Production & 24 & 1831 & 77 & 2002 \\
Sustainability & 10 & 349 & 53 & 2012 \\
Journal of Environmental Management & 21 & 1384 & 39 & 1996 \\
Journal of Material Cycles and Waste Management & 10 & 208 & 29 & 2009 \\
Science of the Total Environment & 12 & 363 & 27 & 2008 \\
Environment and Behavior & 21 & 2018 & 23 & 1994 \\
Ecological Economics & 10 & 458 & 17 & 2002 \\
\hline
\end{tabular}

TC: total citations; N: number of publications; PY: year of first publication.

\subsection{Collaboration Network Analysis}

Collaboration networks demonstrate how authors, institutions and countries relate to each other, thus helping us to understand the social structure in our field of research. Figure 4 maps the collaboration between the 50 most productive authors. The colors in the figure represent different clusters formed by the academic communities, which indicate a few groups of authors collaborating closely. The size of the nodes refers to the number of co-authored articles published by each author, while the thickness of the links between the nodes indicates the degree of cooperation between certain authors. Five main clusters appear in the network, dominated by Harder MK, Wang H, Williams ID, Chen H, and Astrup TF. The map shows a very strong link between Harder MK and Woodard R, even though they barely collaborate with other authors. Williams ID and Astrup TF also dominate relatively small work groups. As a comparison, the clusters centered on Chen $\mathrm{H}$ and Wang $\mathrm{H}$ have a higher density and have more authors included. The two groups are also younger than others, as most authors within them started to publish their first articles after 2014. Overall, the collaboration network is discrete as there is no connection between many clusters. Some influential authors like Read AD do not have a stable community to work with, while the younger generations (e.g., Chen $\mathrm{H}$, Wang $\mathrm{H}$ ) tend to collaborate more with others. 


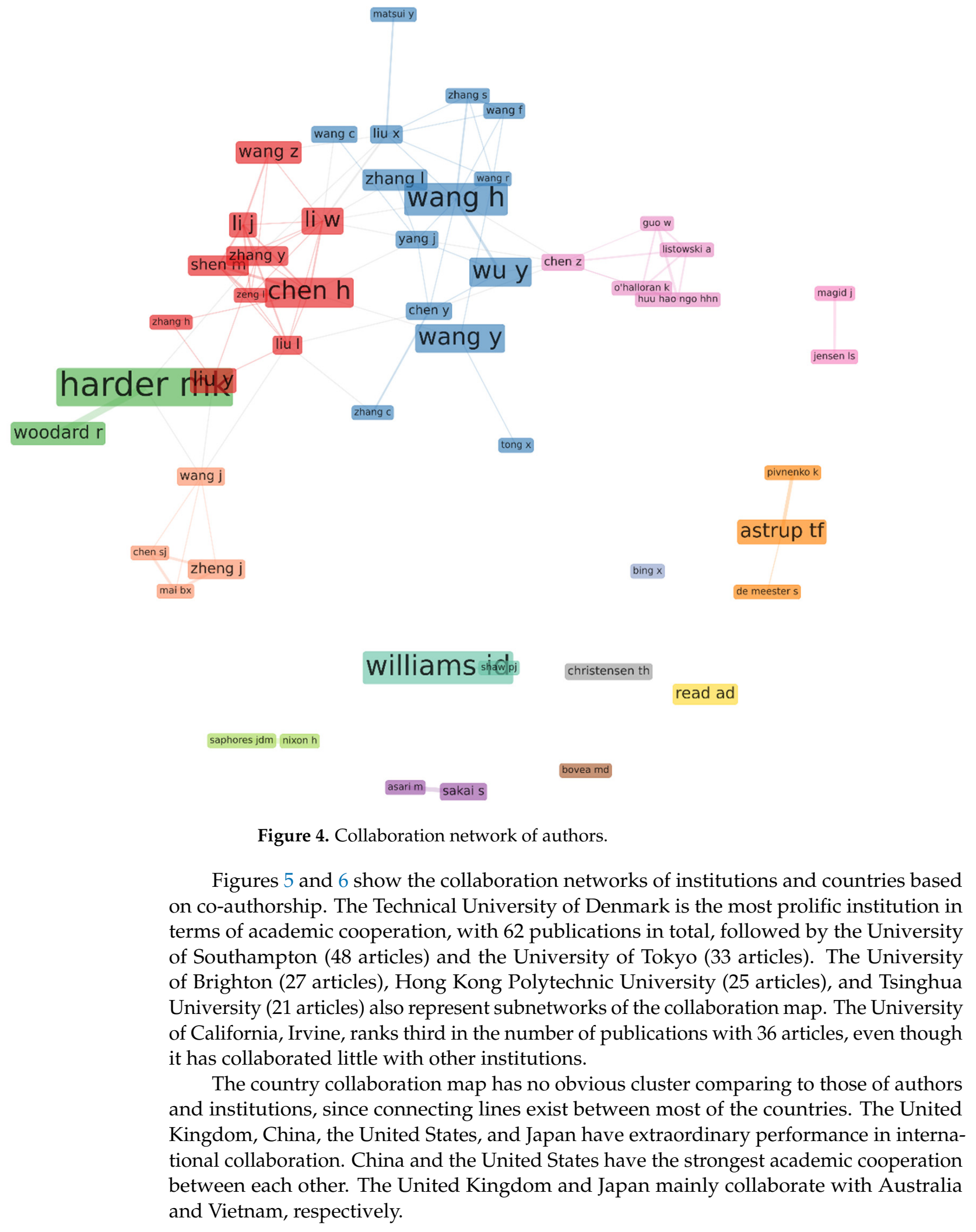




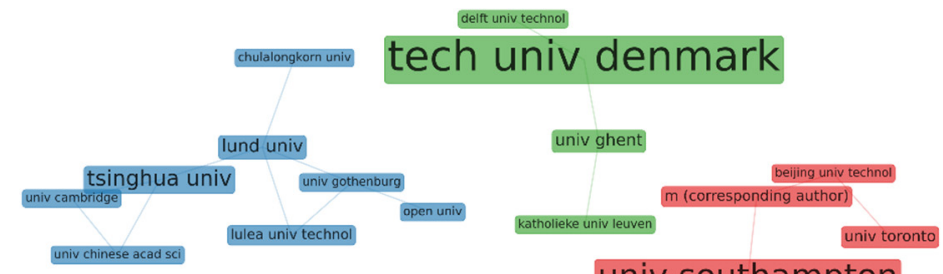

univ southampton

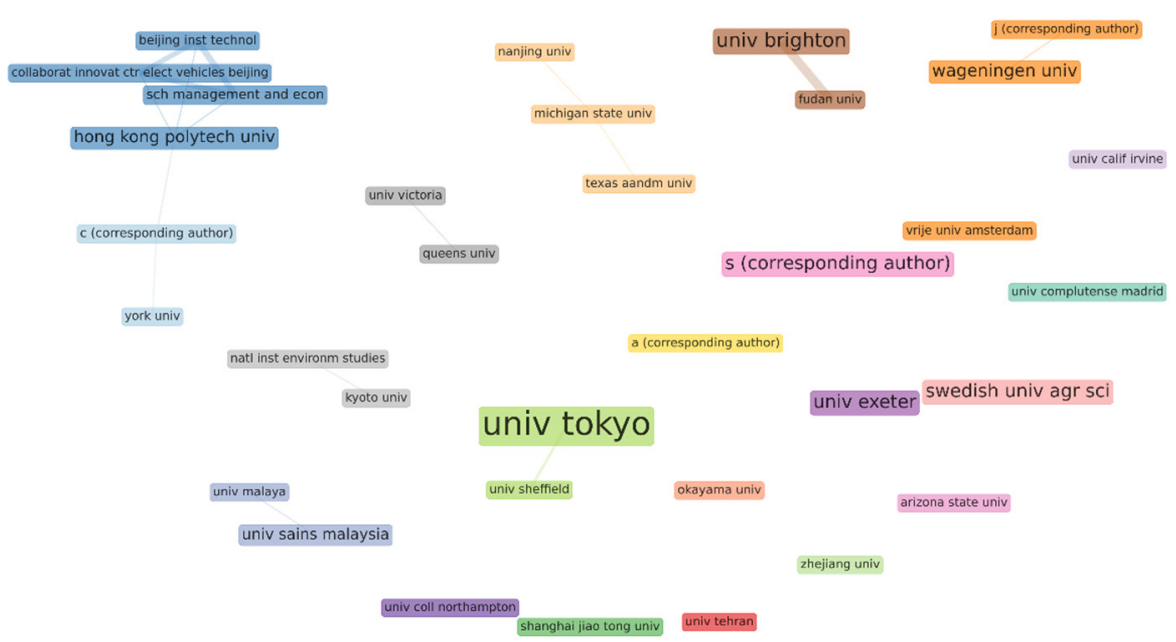

Figure 5. Collaboration network of institutions.

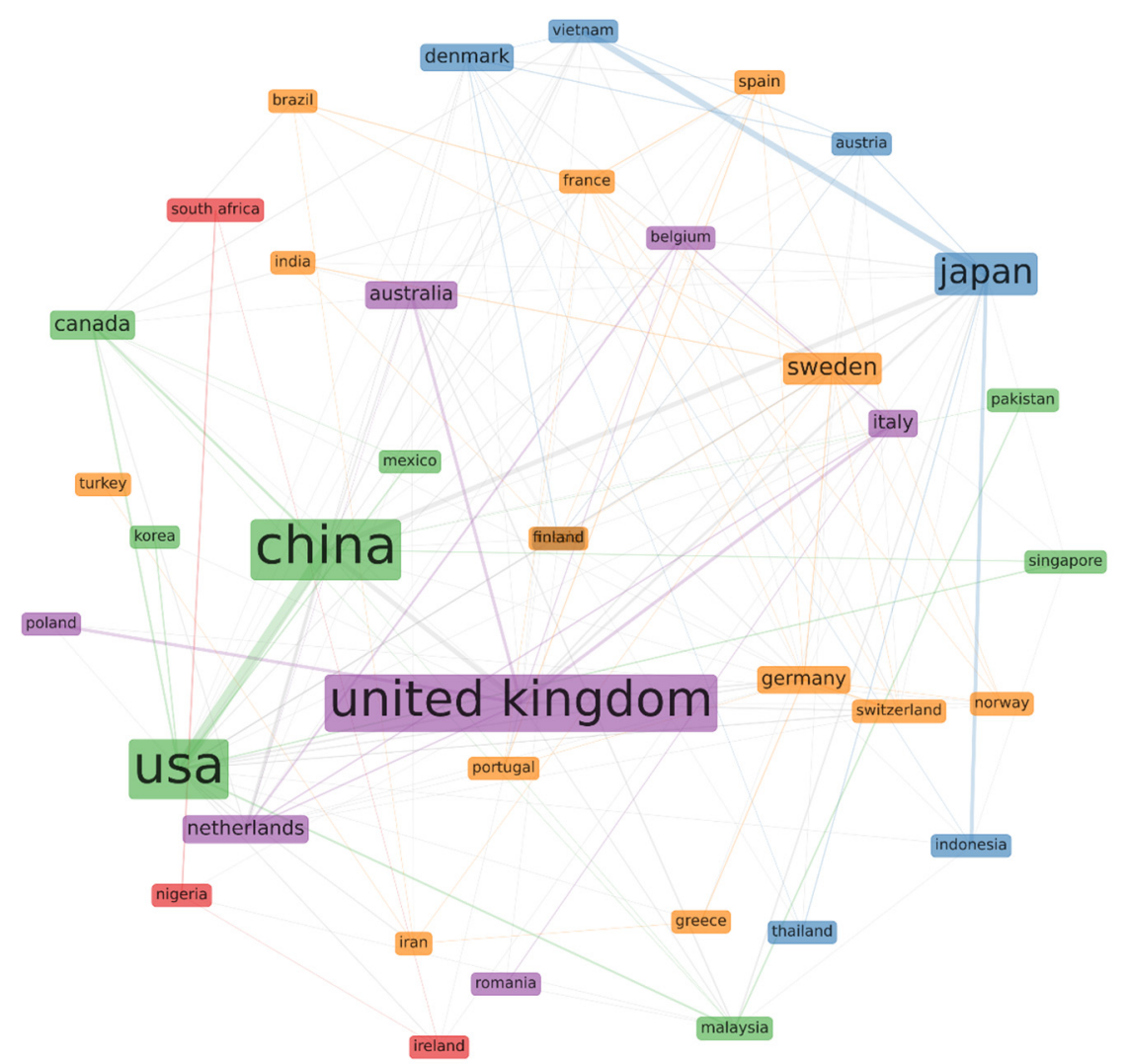

Figure 6. Collaboration network of countries. 


\subsection{Citation Analysis}

Table 4 lists the most cited articles in the dataset. The paper Twenty Years after Hines, Hungerford, and Tomera: A New Meta-analysis of Psycho-social Determinants of Pro-environmental Behaviour, published by Bamberg and Möser [49] in 2007, has drawn the most attention from the academic communities with 1367 total citations. Based on 57 previous empirical studies about correlations between psycho-social variables and pro-environmental behavior, this article conducted a meta-analytic structural equation modelling test and confirmed that personal pro-environmental behavioral intention was determined by attitude, behavior control, personal moral norm, and problem awareness. This intention eventually mediated the impact of all other psycho-social variables on pro-environmental behavior, including household waste recycling.

Table 4. Top 10 global citated articles on household waste recycling.

\begin{tabular}{|c|c|c|c|}
\hline $\mathbf{R}$ & Reference & Title & TC \\
\hline 1 & $\begin{array}{l}\text { Bamberg and Möser (2007) } \\
\text { [49] }\end{array}$ & $\begin{array}{l}\text { Twenty years after Hines, Hungerford, and Tomera: A new meta-analysis } \\
\text { of psycho-social determinants of pro-environmental behaviour }\end{array}$ & 1367 \\
\hline 2 & Tuomela (2000) [50] & Biodegradation of lignin in a compost environment: A review & 630 \\
\hline 3 & Barr (2007) [51] & Factors influencing environmental attitudes and behaviors & 367 \\
\hline 4 & Tonglet et al. (2004) [47] & $\begin{array}{l}\text { Using the theory of planned behaviour to investigate the determinants of } \\
\text { recycling behaviour: A case study from Brixworth, UK }\end{array}$ & 364 \\
\hline 5 & $\begin{array}{l}\text { Troschinetz and Mihelcic } \\
\text { (2009) [3] }\end{array}$ & Sustainable recycling of municipal solid waste in developing countries & 283 \\
\hline 6 & Quested et al. (2013) [52] & Spaghetti soup: The complex world of food waste behaviours & 274 \\
\hline 7 & Carrus et al. (2008) [53] & $\begin{array}{l}\text { Emotions, habits and rational choices in ecological behaviours: The case of } \\
\text { recycling and use of public transportation }\end{array}$ & 269 \\
\hline 8 & Gamba and Oskam (1994) [54] & $\begin{array}{l}\text { Factors influencing community residents' participation in commingled } \\
\text { curbside recycling programs }\end{array}$ & 259 \\
\hline 9 & Taylor and Todd (1995) [55] & An integrated model of waste management behavior & 220 \\
\hline 10 & Mannetti et al. (2004) [56] & Recycling: Planned and self-expressive behaviour & 211 \\
\hline
\end{tabular}

R: ranking; TC: total citations.

Most of the widely cited articles focus on the influencing factors behind individual's recycling intention or behavior. Environmental values [51], previous recycling experience [57], personal education on waste management [3], anticipated emotions [53], environmental knowledge [54], and personal identity [56] are also identified as significant factors by various studies on household recycling. In addition to the studies that treat household waste as a broad concept, there are also some articles focusing on specific types of waste, such as compostable packages [50] and food waste [52]. The top ten articles ranked by global citations are published in five different journals, within which Journal of Environmental Psychology and Environment and Behavior have both published 3 articles, indicating that psychological methods and behavioral studies are the hotspots in this field.

To further identify the most important articles that have made great contributions within the research field of household waste recycling, local citation is introduced as another indicator to measure the influence. Local citation measures how many times an article included in our data collection has been cited by other articles also in the collection. As listed in Table 5, some of the most local cited articles have a relatively lower number of global citations, indicating that these studies mainly draw attention in the specific research area of household waste recycling. Like the articles with high global citations, many of the most local cited studies also focus on the determinants of recycling intention and behavior. However, some other studies treat recycling from the perspective of economics and policy. Kinnaman and Fullerton [58] estimated the impact of garbage fees and found that correction for endogenous local policy increases the effect of garbage fees on recycling. Dahlen et al. [59] compared the efficiency of different waste collection systems and confirmed that weight-based billing reduced a greater amount of waste than a fixed garbage fee. The 
rise in the waste collection fee induced residents to recycle more according to the article published by Hong [60] in 1999.

Table 5. Top 10 local citated articles in household waste recycling.

\begin{tabular}{|c|c|c|c|c|}
\hline $\mathbf{R}$ & Reference & Title & LCS & GCS \\
\hline 1 & Gamba and Oskam (1994) [54] & $\begin{array}{l}\text { Factors influencing community residents' participation in } \\
\text { commingled curbside recycling programs }\end{array}$ & 72 & 259 \\
\hline 2 & Bartelings and Sterner (1999) [61] & $\begin{array}{l}\text { Household waste management in a Swedish municipality: } \\
\text { Determinants of waste disposal, recycling and composting }\end{array}$ & 66 & 147 \\
\hline 3 & Knussen et al. (2004) [62] & $\begin{array}{l}\text { An analysis of intentions to recycle household waste: The roles of } \\
\text { past behaviour, perceived habit, and perceived lack of facilities }\end{array}$ & 59 & 170 \\
\hline 4 & Kinnaman and Fullerton (2000) [58] & Garbage and recycling with endogenous local policy & 55 & 108 \\
\hline 5 & Saphores et al. (2006) [63] & Household willingness to recycle electronic waste & 55 & 144 \\
\hline 6 & Chan (1998) [64] & $\begin{array}{l}\text { Mass communication and pro-environmental behaviour: Waste } \\
\text { recycling in Hong Kong }\end{array}$ & 50 & 166 \\
\hline 7 & Barr (2007) [51] & Factors influencing environmental attitudes and behaviors & 48 & 367 \\
\hline 8 & Berglund (2006) [65] & $\begin{array}{l}\text { The assessment of households' recycling costs: The role of personal } \\
\text { motives }\end{array}$ & 42 & 84 \\
\hline 9 & Dahlen et al. (2007) [59] & $\begin{array}{l}\text { Comparison of different collection systems for sorted household } \\
\text { waste in Sweden }\end{array}$ & 40 & 88 \\
\hline 10 & Hong (1999) [60] & $\begin{array}{l}\text { The effects of unit pricing system upon household solid waste } \\
\text { management: The Korean experience }\end{array}$ & 36 & 78 \\
\hline
\end{tabular}

R: ranking; LCS: local citations; GCS: global citations.

Since we have already analyzed the most global-cited and local-cited papers, Table 6 lists articles that have been cited the most by the 1295 articles in our data. These articles have either developed theoretic models or provided empirical research examples for the later studies on household waste recycling. The theory of planned behavior (TPB) proposed by Ajzen [66] has been widely adopted to explain individual's recycling intention and behavior. The article about TPB published by Ajzen in 1991 has been cited 108 times by the publications on household waste recycling in our data. TPB assumes that people's intention to perform a certain behavior is mediated by attitude, subjective norm, and perceived behavior control. When applying TPB to household recycling behavior, various researchers introduced additional variables to improve the explanatory power of the theoretic framework, such as moral norm, awareness of consequences [47], past behavior [67], convenience [49], local norm [68], and habits [18].

Table 6. Top 10 articles cited the most by articles in the data.

\begin{tabular}{|c|c|c|c|}
\hline $\mathbf{R}$ & Reference & Title & TC \\
\hline 1 & Ajzen (1991) [66] & The theory of planned behavior. & 108 \\
\hline 2 & Vining and Ebreo (1990) [69] & What makes a recycler: A comparison of recyclers and nonrecyclers & 94 \\
\hline 3 & Jenkins et al. (2003) [70] & $\begin{array}{l}\text { The determinants of household recycling: A material-specific analysis of } \\
\text { recycling program features and unit pricing }\end{array}$ & 85 \\
\hline 4 & Tonglet et al. (2004) [47] & $\begin{array}{l}\text { Using the theory of planned behaviour to investigate the determinants of } \\
\text { recycling behaviour: A case study from Brixworth, UK }\end{array}$ & 85 \\
\hline 5 & $\begin{array}{l}\text { Fullerton and Kinnaman } \\
\text { (1996) [71] }\end{array}$ & Household responses to pricing garbage by the bag & 80 \\
\hline 6 & Oskamp et al. (1991) [72] & Factors influencing household recycling behavior & 75 \\
\hline 7 & Gamba and Oskam (1994) [54] & $\begin{array}{l}\text { Factors influencing community residents' participation in commingled } \\
\text { curbside recycling programs }\end{array}$ & 72 \\
\hline 8 & Hornik et al. (1995) [73] & Determinants of recycling behavior: A synthesis of research results & 70 \\
\hline 9 & Martin et al. (2006) [23] & $\begin{array}{l}\text { Social, cultural and structural influences on household waste recycling: a } \\
\text { case study }\end{array}$ & 70 \\
\hline 10 & Schultz et al. (1995) [74] & Who recycles and when? A review of personal and situational factors & 67 \\
\hline
\end{tabular}


Finally, we perform a historiographic analysis on the data as proposed by Garfield [75] and plot a chronological direct citation network named historiography [24] (Figure 7). The historiograph helps us quickly identify the most significant works on household waste recycling and trace their year-by-year historical development.

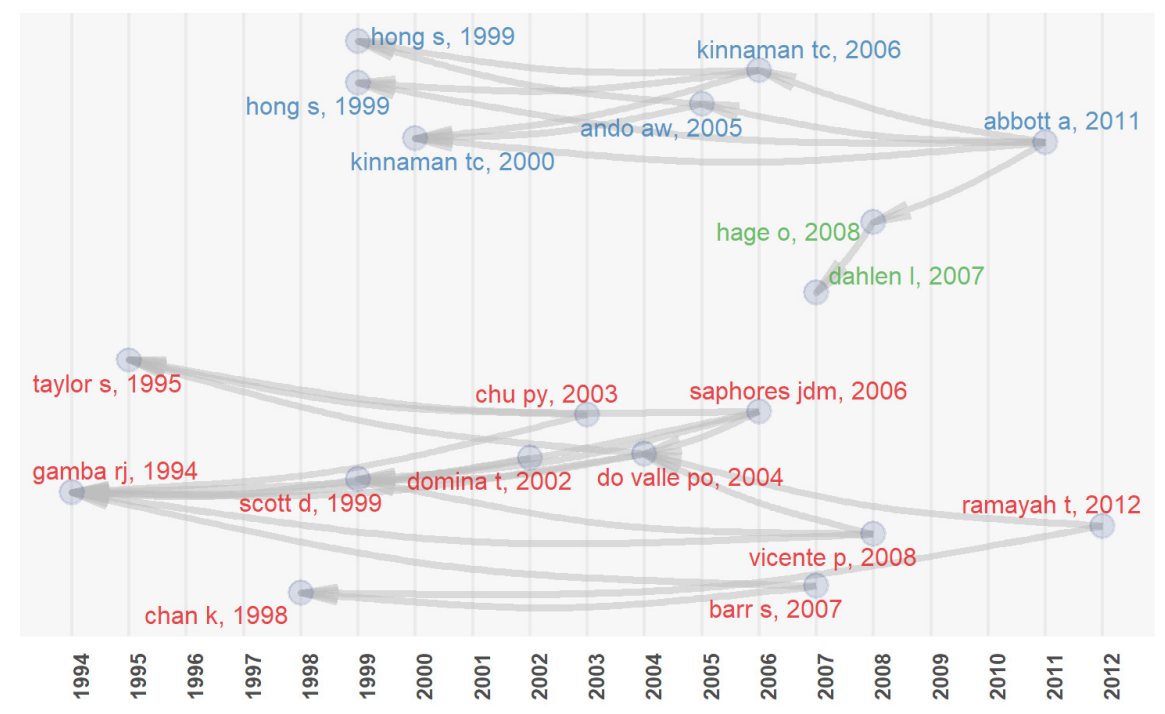

Figure 7. Historiograph top-cited papers in the field of household waste recycling.

The earliest node is the paper Factors Influencing Community Residents' Participation in Commingled Curbside Recycling Programs published by Gamba RJ [54] in 1994. In this paper, a mail survey sent to households in a suburb with a new commingled curbside recycling program discovered an inconsistency between self-reported participation and observed actual recycling behavior. Relevant recycling knowledge was found to be the most significant predictor of observed recycling behavior. Gamba's study has thereafter inspired many of the top-cited articles in the historiograph.

Hong S published two important articles that have triggered four citation chains in 1999. The first paper, The Effects of Unit Pricing System Upon Household Solid Waste Management: The Korean Experience, is a single-author article published in Journal of Environmental Management [60]. The second paper, Household Responses to Price Incentives for Recycling: Some Further Evidence, published in Land Economics, is a collaboration with Adam RM [76]. The two papers both studied the effects of price incentives on household recycling but in different places: 20 cities in South Korea, and Portland, USA. Results from the two empirical studies show that households would recycle more when facing an increase in waste disposal service fees. Meanwhile, according to the study in South Korea, the demand for waste collection services does not necessarily decrease with additional increases in the collection fee unless further recycling incentives are accompanied.

As can be seen in the historiograph, the historical direct citation network of top-cited papers is divided into two subnetworks. One starts from Gamba RJ, 1994, and the other starts from Hong S, 1999. The subnetwork in the lower part of the graph, marked in red, commits to understanding people's recycling intentions and behavior from the perspective of social psychology, while articles in the upper part marked in blue apply economic models to studies of garbage fees. This dispersion observed from the historiograph indicates the two main perspectives on the research of household waste recycling. Some researchers also interacted with the two perspectives in their studies. As marked in green in Figure 7, the paper Norms and Economic Motivation in Household Recycling: Empirical Evidence from Sweden, published by Hage O [77] in 2008, built a theoretical framework that integrated norm-motivated behavior into an economic model and confirmed that both economic and moral motives could influence household recycling rates. 


\subsection{Conceptual Structure Analysis}

\subsubsection{Descriptive Analysis of High-Frequency Keywords}

Keywords are the high-level summarization and refinement of the article core [78]. There are 3545 keywords provided by the authors, and 67 keywords meet the threshold of 10 occurrences. Of the keywords, 2835 only appear once, accounting for $80 \%$ of the total amounts, which reflects great diversity of the research field. The most frequent keyword, "recycling", occurs in 343 articles, as it is included in the searching keywords in the data collection process. To eliminate the interference of repeated keywords and more accurately identify research hotspots, we exclude the homogeneous keywords that are highly similar to our search keywords, as well as the overly broad concepts concerning environmental studies. The excluded keywords and their occurrences are as follows: "recycling" (343), "waste management" (108), "waste" (88), "household waste" (69), "municipal solid waste" (50), "solid waste" (36), "solid waste management" (30), "management" (27), "waste recycling" (25), "household" (22), "analysis" (19), "environment" (18), "environmental" (17), "waste collection" (17), "household recycling" (16), "household solid waste" (15), "households" (15), "survey" (14), "municipal waste" (12), "municipal solid waste management" (10), and "recycle" (10). Some other keywords with similar meanings are merged: "sustainability" and "sustainable development"; "food waste" and "organic waste"; "recycling behavior", "recycling behaviour", and "behaviour"; "life cycle assessment", "LCA", and "material flow analysis"; "WEEE", "e-waste", and "electronic waste"; "source separation", "waste separation", "separation", and "waste sorting"; "plastic waste", "plastics", and "plastic recycling"; "policy" and "environmental policy".

Table 7 lists the high-frequency keywords after filtering. As can be seen from the list, the research field of household waste recycling has been extended to all other processes in the waste management chain, including waste generation (11 occurrences), waste collection (31 occurrences), source separation (57 occurrences), and disposal (11 occurrences). In this context, life cycle assessment, defined as "a technique to compile and analyze the environmental impacts involved in all stages of the product's life cycle from raw material extraction stage to the disposal stage" [79], is widely used in waste recycling studies.

Table 7. Most relevant keywords meeting the threshold of 10 occurrences.

\begin{tabular}{cccc}
\hline Keyword & Occurrences & Keyword & Occurrences \\
\hline electronic waste & 69 & theory of planned behavior & 17 \\
source separation & 57 & landfill & 14 \\
life cycle assessment & 56 & reverse logistics & 14 \\
recycling behavior & 52 & social norms & 13 \\
sustainability & 45 & willingness to pay & 13 \\
organic waste & 39 & disposal & 11 \\
circular economy & 37 & questionnaire survey & 11 \\
plastic waste & 33 & recovery & 11 \\
attitudes & 29 & Vietnam & 11 \\
composting & 26 & waste generation & 11 \\
China & 25 & consumption & 10 \\
policy & 22 & informal sector & 10 \\
incineration & 21 & participation & 10 \\
packaging waste & 20 & urban & 10 \\
reuse & 19 & waste reduction & 10 \\
\hline
\end{tabular}

The following terms in the table are merged with the keywords in the brackets: source separation (waste separation, separation, waste sorting); life cycle assessment (LCA, material flow analysis); recycling behavior (recycling behaviour, behaviour); sustainability (sustainable development); organic waste (food waste); electronic waste (WEEE, e-waste); plastic waste (plastics, plastic recycling); attitudes (attitude); policy (environmental policy).

Sustainable development and the circular economy are two important concepts that drive the studies of waste recycling. Household waste recycling as a part of municipal solid waste management is the foundation for a circular economy to achieve more waste 
prevention and better resource management. Even though various studies have discussed waste recycling in the context of the circular economy and sustainable development, the relationships between them are still blurred as these concepts have been diffuse since they were proposed [30]

The keyword list also shows that personal recycling behavior is the most popular research object of the articles. The theory of planned behavior is widely used in relevant behavioral studies. Attitude and social norm are the most studied predictors of recycling behavior.

In all types of household waste, waste from electrical and electronic equipment (WEEE), food waste and organic waste, plastic waste, and packaging waste are mentioned the most by the authors. Waste reduction and reuse, as another two elements of the three Rs (reduce, reuse, recycle), have been discussed frequently with household recycling.

Despite the original keywords provided by the authors, our data also includes another type of keywords, namely keywords plus. Keywords plus are generated from the titles of an article's references based upon a unique algorithm [80]. Compared with authors' keywords, keywords plus are more broadly descriptive but less comprehensive in presenting the content of a specific article [81]. Figure 8 presents the yearly occurrences of the top 10 keywords plus terms. Household waste recycling has been treated mostly as a management issue, as the term "management" occurs a lot more than the other terms during the past 10 years. "Recycling behavior" draws little attention around 2010, but since then, the number of its occurrences has increased the most rapidly. On the contrary, "participation" is the only one of the 10 most relevant keywords plus terms that has declined in recent years.

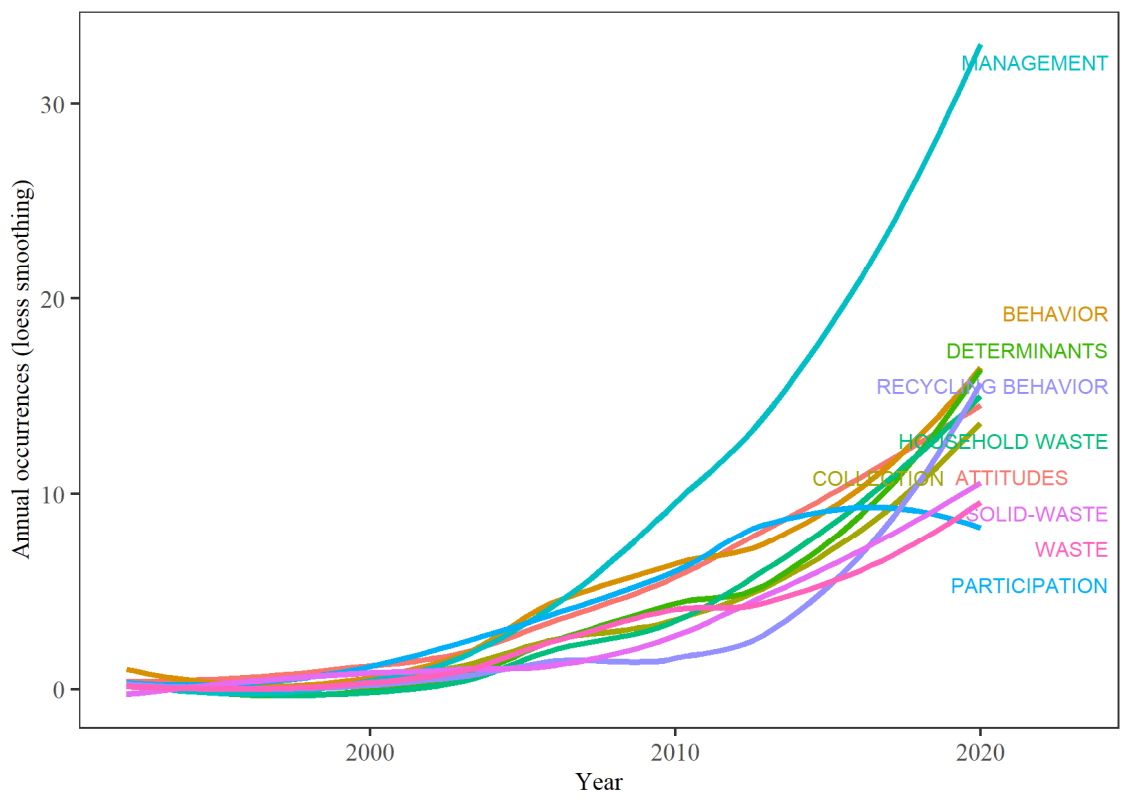

Figure 8. Annual occurrences of the most relevant keywords plus terms generated by WoS.

\subsubsection{Cluster Analysis of High-Frequency Keywords}

Using multiple correspondence analysis, the conceptual structure maps of authors' keywords and keywords plus are generated, and the keywords clusters are plotted in two-dimensional maps (Figures 9 and 10). The closer the points representing each keyword are on the graph, the more similar the distribution of the keywords are, which means they co-occur in the articles more frequently. Moreover, the proximity of a keyword to the center point represents its popularity in the research field. Keywords around the center have received high attention from the research community, while those by the edge are less related to other research topics [82]. 


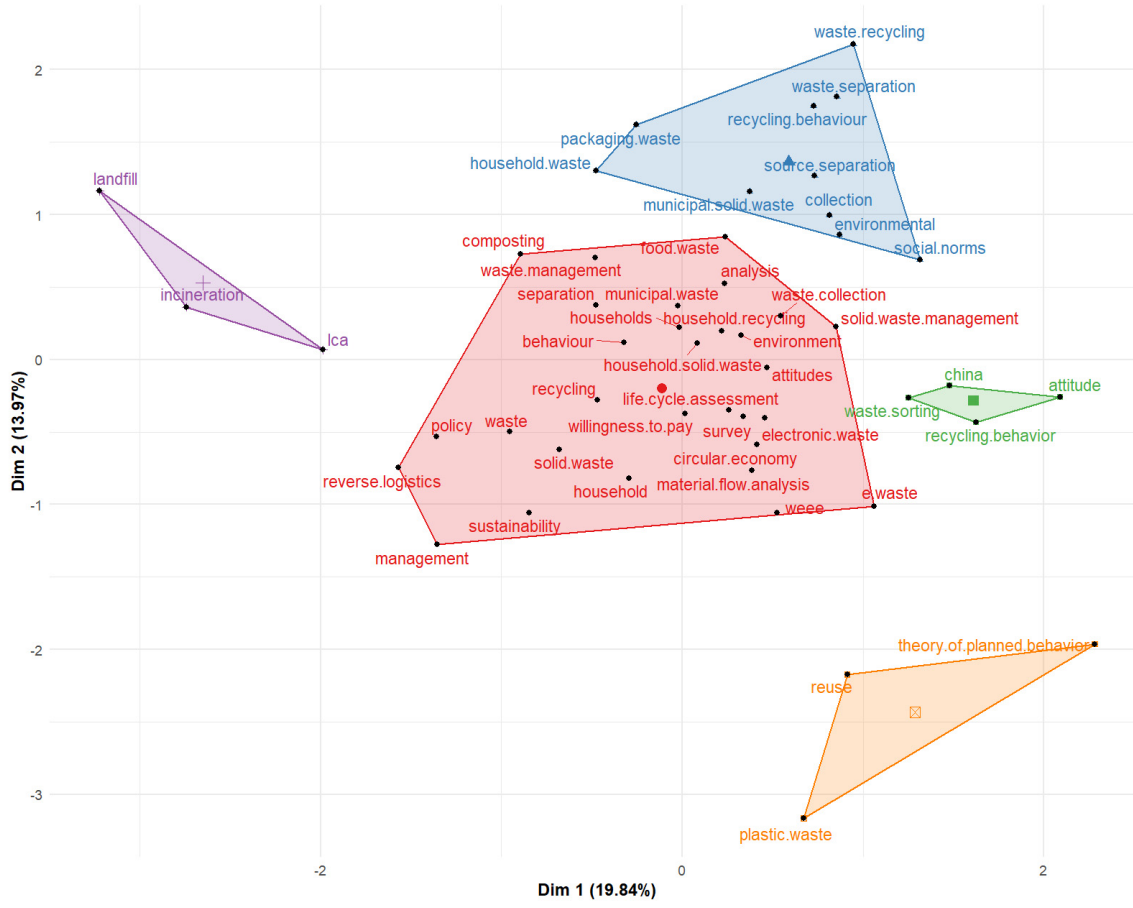

Figure 9. Cluster analysis of the authors' keywords using multiple correspondence analysis.

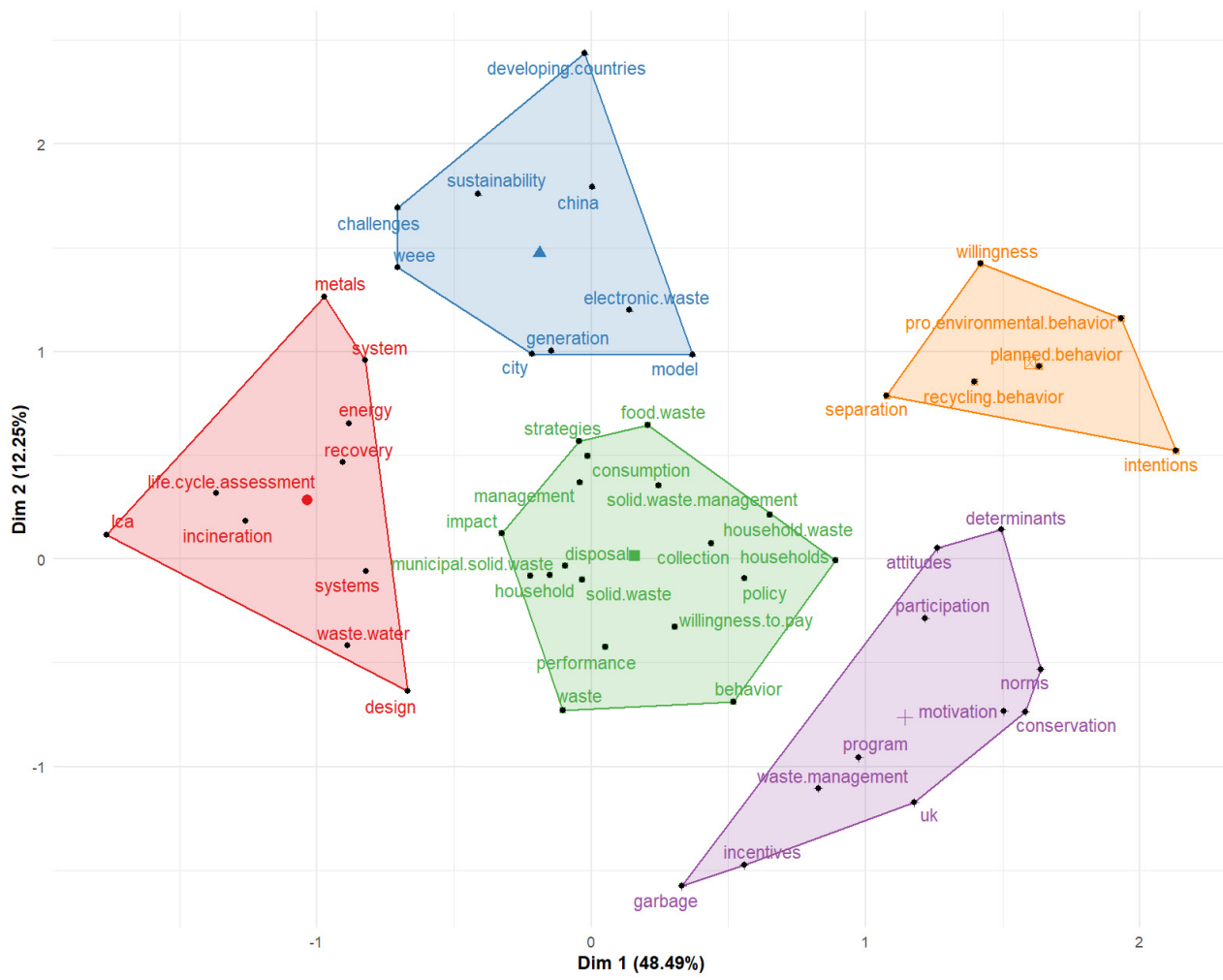

Figure 10. Cluster analysis of the keywords plus using multiple correspondence analysis.

In terms of authors' keywords, we can infer from Figure 9 that the keywords are grouped into two major clusters and three minor clusters:

(1) The first major cluster marked in red in the center of the graph involves most of the important concepts regarding the research field and is highly consistent with the topic of household waste recycling. "Behavior", "attitudes", and "willingness to pay" are the 
main research variables of this group of studies. "Life cycle assessment", "material flow analysis", and "reverse logistics" have also been emphasized in this cluster. Apart from the general sense of household waste, more specific types of waste, including food waste and electronic waste, have attracted considerable research interest.

(2) The second major cluster, which is marked in blue and located in the upper right part of the graph, is more related to studies on waste source separation.

(3) The first minor cluster, marked in purple on the left side of the graph, is dedicated to the study of traditional waste disposal methods, including landfill and incineration. Life cycle assessment (LCA) is a commonly used technique in these kinds of studies.

(4) The second cluster, marked in green on the right side of the graph, is mainly related to waste sorting, recycling behavior, attitude, and research carried out in China.

(5) The last minor cluster, marked in yellow on the bottom right, is mainly related to the reuse of plastic waste and the application of the theory of planned behavior.

Overall, Figure 9 shows the distribution pattern of authors' keywords, demonstrating that household waste recycling, as the core research topic, is surrounded by other related topics such as source separation, reuse, and final disposal.

The co-occurrence of the keywords plus is more uniformly distributed. As can be seen from Figure 10, five clusters with similar scales are generated using multiple correspondence analysis:

(1) The first cluster, marked in red, focuses more on the technical and engineering aspects. High-frequency keywords that dominate this cluster are life cycle assessment (LCA), incineration, recovery, systems, and energy.

(2) The second cluster, marked in blue, focuses on electronic waste (WEEE) and sustainability. The research areas of the studies in this cluster are mainly China and other developing countries.

(3) The third cluster, marked in green, is dedicated to household solid waste management. Collection, consumption, willingness to pay, performance, and disposal are important topics in this group of studies.

(4) The fourth cluster, marked in yellow, is related to numerous studies that apply the theory of planned behavior. This popular theory in the field of pro-environmental behavior is not only applicable to recycling behavior but also widely used in studies of source separation.

(5) The last cluster, marked in purple, is mainly related to concepts and topics under social psychology. Top contributing keywords in this cluster are motivation, norms, incentives, attitude, program, and determinants. The United Kingdom (UK) also appears in this cluster, indicating that many of the studies from the perspective of social psychology are contributed by British scholars.

\subsubsection{Thematic Evolution Analysis}

The clusters of keywords obtained from the co-word analysis are considered as themes of our research field [83]. We further created a thematic map (Figure 11) based on co-word network analysis and clustering. The thematic map, also referred to as the strategic diagram [84,85], describes two parameters ("centrality" and "density") that characterize the themes in a two-dimensional space. Centrality measures to what extent a network interacts with other networks. The centrality of a theme represents the strength of its external connections to other themes and can be used as an indicator to measure the influence of the theme in the entire research field. Density measures the strength of internal ties among all the keywords within a theme. Therefore, the density of a given theme represents its development. 


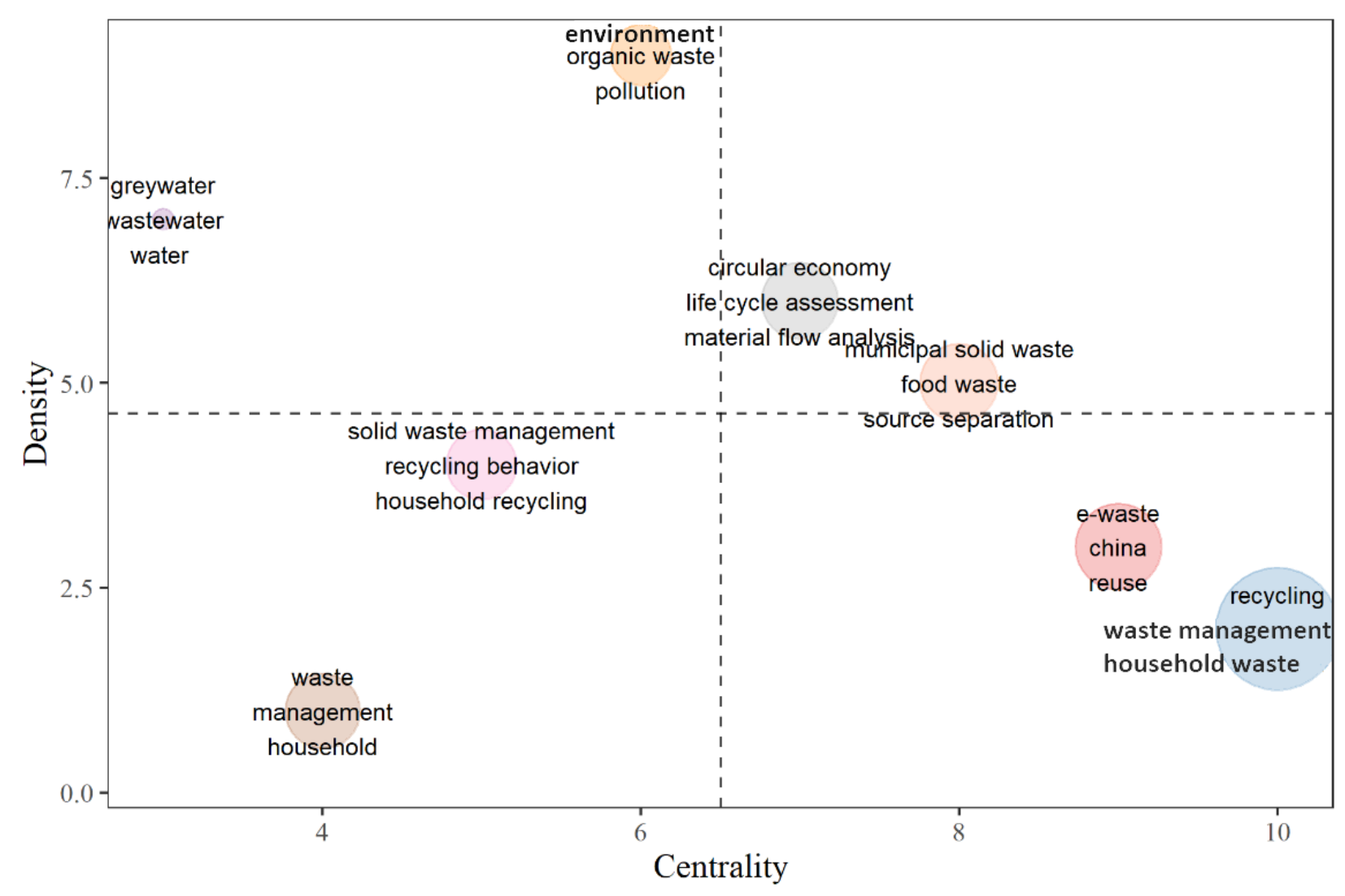

Figure 11. Thematic map of authors' keywords based on co-word network analysis and clustering.

Based on their centrality and density, the themes distributed in four quadrants in Figure 11 are defined by the following four categories [83,84,86,87]:

- Motor themes in the upper-right quadrant. Such themes are both fully developed and vital to the research field.

- Specialized and peripheral themes in the upper left quadrant. Given that these themes have a relatively higher density but lower centrality, they are isolated and have limited influence on the field despite their distinctive internal development.

- $\quad$ Emerging or declining themes in the lower left quadrant. The themes of this category are weakly developed and marginal to the research field.

- Basic and transversal themes in the lower right quadrant. They are not yet fully developed, but they have a very important position in the field of research.

According to the strategic diagram generated using authors' keywords from our data, we can observe eight main themes with different levels of density and centrality. What stands out is that different types of waste differ greatly in their positions in the figure. Electronic waste (e-waste), belonging to the basic and transversal themes, has a much higher centrality but lower density compared with other types of waste. Greywater has the lowest centrality, implying that this specialized theme is relatively peripheral and marginal in our field of research. The theme represented by "circular economy", "life cycle assessment", and "material flow analysis" has its centrality and density both above the average line. However, the upper right part of the strategic diagram is still vacant, indicating that motor themes still need to be found in future studies.

In the last part of this section, we perform thematic evolution analysis and map the results with a Sankey diagram (Figure 12). The Sankey diagram helps us clarify the quantity and direction of thematic flow and conversion relationships between the themes [88]. 


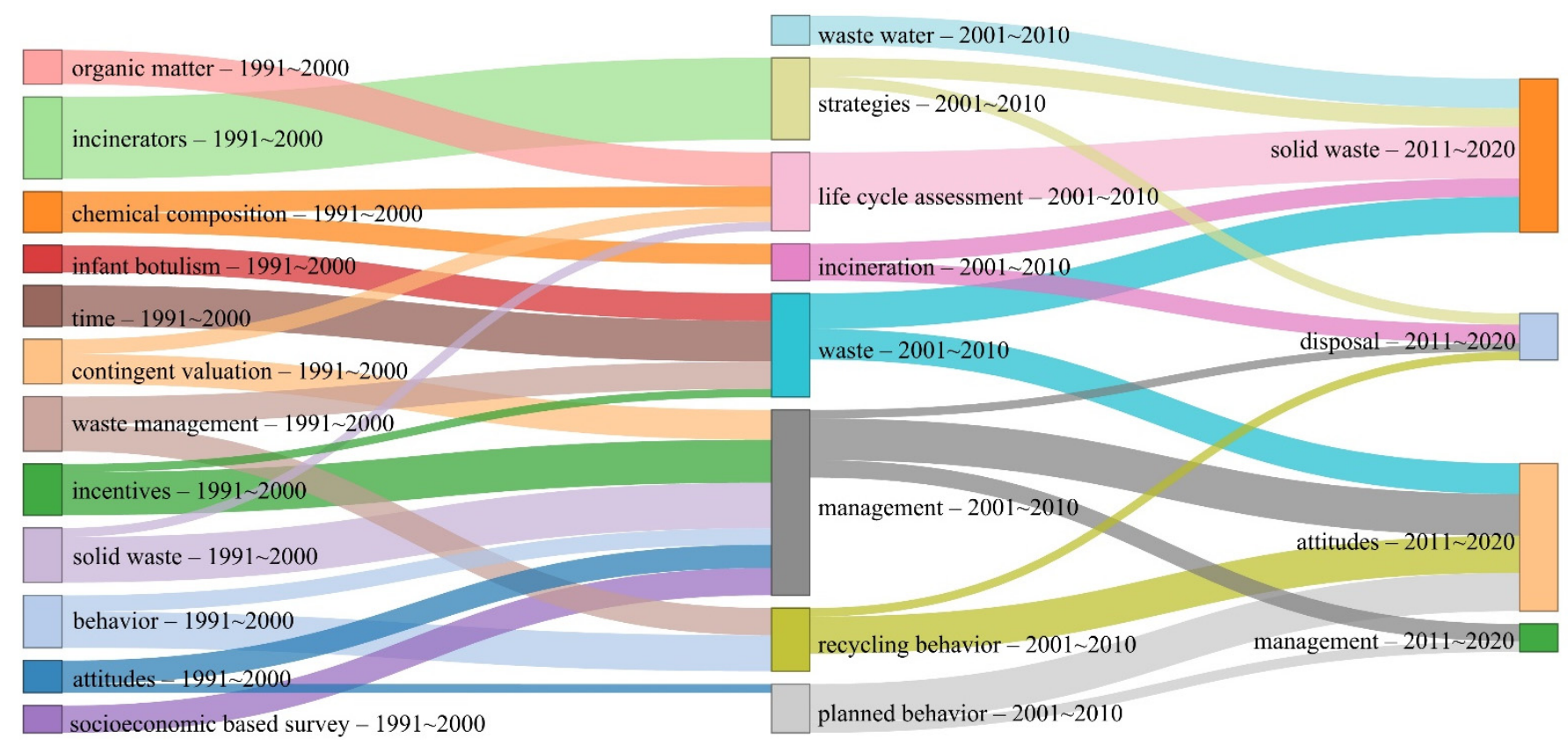

Figure 12. Thematic evolution of the research field of household waste recycling (1991-2020).

The timespan of our data is evenly divided into three slices with two cutting years, 2000 and 2010. The nodes in the diagram represent the main research themes generated form the co-word network analysis in each time slice. The text labels next to the nodes indicate the core keywords of the themes as well as the time slices. The number of keywords included in each theme is represented by the size of the corresponding node. Themes from adjacent time slices are connected by streamlines when they share the same keywords. The width of the streamlines is proportional to the number of keywords shared by the connected themes and indicates the relevance between them.

From Figure 12, we can see that as the research progresses, the pattern of research themes has gradually shifted from decentralization to uniformity. In the early stage (19912000), various themes are dominated by specialized and unrelated keywords, such as "incinerators", "chemical composition", "contingent valuation", "incentives", and "behavior". In the second stage (2001-2010), the methodology of life cycle assessment and the theory of planned behavior have been established, developed, and widely used in the research field. Under the theme of "management", numerous interdisciplinary studies have emerged from isolated themes, including "contingent valuation", "incentives", "solid waste", "behavior", "attitudes", and "socioeconomic based survey" in the first stage. In the third stage (2011-2020), the comprehensiveness of the research field is further enhanced, as different themes from the former time slices merge again into new themes.

\section{Conclusions}

Municipal solid waste problems have attracted increasing concerns, and several studies have systematically reviewed the field of related topics. Since household waste recycling is a key concept in municipal waste management and there is still lack of scientometric studies focusing on it, this paper performed a bibliometric analysis based on the data of 1295 scientific publications obtained from Web of Science using the open-source R language and bibliometrix package.

The analysis of scientific productivity shows that the research field of household waste recycling is still in the expansion period as annual rapid growth has not slowed down. China is the most productive country in terms of the total number of articles published. However, when taking into consideration the number of citations as an indicator of academic influence, the United Kingdom and the USA have surpassed China. Ian Williams, Marie Harder, and Adam Read are the most prolific authors, and they are all 
affiliated with institutes in the UK. Beginning in the 2010s, researchers from China has become increasingly influential in terms of both the quantity and the quality of scientific productions, challenging the dominance of British scholars. Resources, Conservation and Recycling and Waste Management published influential studies on household waste recycling.

Collaborative network analysis reveals that younger generations tend to cooperate more with each other in their studies than senior scholars. As the two countries with the most academic output, China and the USA also have the closest cooperation relationship, while the UK mainly collaborates with European countries. Among all the institutions, the Technical University of Denmark is the most prolific in terms of academic cooperation.

Citation analysis helps us identify the most influential articles in our research field. A meta-analysis of determinants of pro-environmental behavior, including household waste recycling carried out by Bamberg and Möser [49], has received the greatest interest and got the most citations. In terms of studies not included in our data, the theory of planned behavior, proposed by Ajzen [66], has made the greatest contribution to our field of research. Numerous studies applied this theory to the identification of factors influencing residents' recycling behavior. In general, most of the highly cited articles either focus on socio-psychological or economic perspectives. This trend is also confirmed by historiographic analysis.

The conceptual structure analysis first identifies research hotspots including electronic waste, source separation, life cycle assessment, recycling behavior, and sustainability. Then, keywords are clustered into themes using multiple correspondence analysis, and a strategic diagram is generated. According to the strategic diagram, the circular economy and life cycle assessment are clarified as motor themes that are fully developed and vital to the research field. Organic waste and pollution are specialized and peripheral themes. Electronic waste and reuse are basic and transversal themes that still need further development. Finally, a Sankey diagram generated from thematic evolution analysis demonstrates the patterns of the three stages of thematic evolution. Research themes are specialized and isolated in the first stage (1991-2000). Methodologies and theories are developed and widely applied in the second stage (2001-2010), including life cycle assessment and the theory of planned behavior. In the third stage (2011-2020), interdisciplinary trends are observed as several dispersed themes from previous stages merge into new comprehensive themes.

Our study also contributes to the literature given that new findings have been made with comparisons to previous bibliometric studies in the field of waste management. Li et al. [25] identified pyrolysis of e-waste, biodiesel production from waste oil, and anaerobic digestion of organic waste as the research hotspots in their study of "solid waste reuse and recycling". Tsai et al. [30] concluded that incineration is the top indicator for future study of "municipal solid waste in a circular economy". When focusing on household waste recycling, our study finds out that besides these technological topics, research on personal recycling behavior from the perspective of psychology has attracted even more attention. Household waste recycling is not only an environmental science issue but also a social science issue.

With the findings discussed above, this article may help clarify the current research status and future directions of household waste recycling and have implications for both public authorities and academics. Governing bodies should assess the environmental impacts of different types of waste disposal from the entire life cycle and establish sustainable household waste recycling systems under the guidance of academic research. The influencing factors behind residents' attitudes and willingness to recycle must be seriously considered in the policy-making process. Researchers should pay attention to and seek opportunities for collaboration with institutes and countries that are experts in their specific area of interest, such as China for e-waste studies and the United Kingdom for incentives and personal behavior. Communication and collaboration between institutes need to be strengthened as very limited cooperation has been observed. Finally, despite the interdisciplinary trends appearing in the thematic evolution process, research perspectives 
are still limited as many newly published studies are just repetitions of old ones. Frontier and innovative research need to be explored to push the boundaries of waste management and sustainable development.

Author Contributions: Conceptualization, K.S.; methodology, K.S.; software, K.S.; validation, K.S. and Y.Z.; data curation, K.S.; writing—original draft preparation, K.S.; writing—review and editing, K.S., Y.Z., and Z.Z.; visualization, K.S.; supervision, Z.Z.; project administration, Z.Z. All authors have read and agreed to the published version of the manuscript.

Funding: This research received no external funding.

Institutional Review Board Statement: Not applicable.

Informed Consent Statement: Not applicable.

Data Availability Statement: Web of Science (WoS).

Conflicts of Interest: The authors declare no conflict of interest.

\section{References}

1. Ma, J.; Hipel, K.W. Exploring social dimensions of municipal solid waste management around the globe-A systematic literature review. Waste Manag. 2016, 56, 3-12. [CrossRef] [PubMed]

2. Wang, H.; Liu, X.; Wang, N.; Zhang, K.; Wang, F.; Zhang, S.; Wang, R.; Zheng, P.; Matsushita, M. Key factors influencing public awareness of household solid waste recycling in urban areas of China: A case study. Resour. Conserv. Recycl. 2020, $158,104813$. [CrossRef]

3. Troschinetz, A.M.; Mihelcic, J.R. Sustainable recycling of municipal solid waste in developing countries. Waste Manag. 2009, 29, 915-923. [CrossRef] [PubMed]

4. Ma, J.; Hipel, K.W.; Hanson, M.L.; Cai, X.; Liu, Y. An analysis of influencing factors on municipal solid waste source-separated collection behavior in Guilin, China by using the theory of planned behavior. Sustain. Cities Soc. 2018, 37, 336-343. [CrossRef]

5. Noor, T.; Javid, A.; Hussain, A.; Bukhari, S.M.; Ali, W.; Akmal, M.; Hussain, S.M. Types, Sources and Management of Urban Wastes; Elsevier: Amsterdam, The Netherlands, 2020; pp. 239-263. [CrossRef]

6. Karak, T.; Bhagat, R.M.; Bhattacharyya, P. Municipal solid waste generation, composition, and management: The world scenario. Crit. Rev. Environ. Sci. Technol. 2012, 42, 1509-1630. [CrossRef]

7. Wang, H.; Nie, Y. Municipal solid waste characteristics and management in China. J. Air Waste Manag. Assoc. 2001, 51, 250-263. [CrossRef]

8. Knickmeyer, D. Social factors influencing household waste separation: A literature review on good practices to improve the recycling performance of urban areas. J. Clean. Prod. 2020, 245, 118605. [CrossRef]

9. Gunaratne, T.; Krook, J.; Andersson, H. Current practice of managing the waste of the waste: Policy, market, and organisational factors influencing shredder fines management in Sweden. Sustainability 2020, 12, 9540. [CrossRef]

10. Saphores, J.-D.M.; Nixon, H. How effective are current household recycling policies? Results from a national survey of U.S. households. Resour. Conserv. Recycl. 2014, 92, 1-10. [CrossRef]

11. Zheng, P.; Zhang, K.; Zhang, S.; Wang, R.; Wang, H. The door-to-door recycling scheme of household solid wastes in urban areas: A case study from Nagoya, Japan. J. Clean. Prod. 2017, 163, S366-S373. [CrossRef]

12. Nelles, M.; Grünes, J.; Morscheck, G. Waste management in Germany-Development to a sustainable circular economy? Procedia Environ. Sci. 2016, 35, 6-14. [CrossRef]

13. Wang, H.; Jiang, C. Local nuances of authoritarian environmentalism: A legislative study on household solid waste sorting in China. Sustainability 2020, 12, 2522. [CrossRef]

14. Wan, C.; Shen, G.Q.; Yu, A. Key determinants of willingness to support policy measures on recycling: A case study in Hong Kong. Environ. Sci. Policy 2015, 54, 409-418. [CrossRef]

15. Lizin, S.; Van Dael, M.; Van Passel, S. Battery pack recycling: Behaviour change interventions derived from an integrative theory of planned behaviour study. Resour. Conserv. Recycl. 2017, 122, 66-82. [CrossRef]

16. Botetzagias, I.; Dima, A.-F.; Malesios, C. Extending the theory of planned behavior in the context of recycling: The role of moral norms and of demographic predictors. Resour. Conserv. Recycl. 2015, 95, 58-67. [CrossRef]

17. Miafodzyeva, S.; Brandt, N. Recycling behaviour among householders: Synthesizing determinants via a meta-analysis. Waste Biomass Valorization 2012, 4, 221-235. [CrossRef]

18. Aboelmaged, M. E-waste recycling behaviour: An integration of recycling habits into the theory of planned behaviour. J. Clean. Prod. 2021, 278, 124182. [CrossRef]

19. White, K.M.; Hyde, M.K. The role of self-perceptions in the prediction of household recycling behavior in Australia. Environ. Behav. 2011, 44, 785-799. [CrossRef]

20. Khan, F.; Ahmed, W.; Najmi, A. Understanding consumers' behavior intentions towards dealing with the plastic waste: Perspective of a developing country. Resour. Conserv. Recycl. 2019, 142, 49-58. [CrossRef] 
21. Wang, Z.; Guo, D.; Wang, X. Determinants of residents' e-waste recycling behaviour intentions: Evidence from China. J. Clean. Prod. 2016, 137, 850-860. [CrossRef]

22. Hicks, C.; Dietmar, R.; Eugster, M. The recycling and disposal of electrical and electronic waste in China-Legislative and market responses. Environ. Impact Assess. Rev. 2005, 25, 459-471. [CrossRef]

23. Martin, M.; Williams, I.D.; Clark, M. Social, cultural and structural influences on household waste recycling: A case study. Resour. Conserv. Recycl. 2006, 48, 357-395. [CrossRef]

24. Aria, M.; Cuccurullo, C. Bibliometrix: An R-tool for comprehensive science mapping analysis. J. Informetr. 2017, 11, 959-975. [CrossRef]

25. Li, N.; Han, R.; Lu, X. Bibliometric analysis of research trends on solid waste reuse and recycling during 1992-2016. Resour. Conserv. Recycl. 2018, 130, 109-117. [CrossRef]

26. Wu, H.; Zuo, J.; Zillante, G.; Wang, J.; Yuan, H. Construction and demolition waste research: A bibliometric analysis. Archit. Sci. Rev. 2019, 62, 354-365. [CrossRef]

27. Liu, Y.; Sun, T.; Yang, L. Evaluating the performance and intellectual structure of construction and demolition waste research during 2000-2016. Environ. Sci. Pollut. Res. Int. 2017, 24, 19259-19266. [CrossRef] [PubMed]

28. Gao, Y.; Ge, L.; Shi, S.; Sun, Y.; Liu, M.; Wang, B.; Shang, Y.; Wu, J.; Tian, J. Global trends and future prospects of e-waste research: A bibliometric analysis. Environ. Sci. Pollut. Res. Int. 2019, 26, 17809-17820. [CrossRef] [PubMed]

29. Zhang, L.; Geng, Y.; Zhong, Y.; Dong, H.; Liu, Z. A bibliometric analysis on waste electrical and electronic equipment research Environ. Sci. Pollut. Res. Int. 2019, 26, 21098-21108. [CrossRef]

30. Tsai, F.M.; Bui, T.-D.; Tseng, M.-L.; Lim, M.K.; Hu, J. Municipal solid waste management in a circular economy: A data-driven bibliometric analysis. J. Clean. Prod. 2020, 275, 124132. [CrossRef]

31. Wang, C.; Liu, D.; Li, Y.; Wang, L.; Gu, W. A multidisciplinary perspective on the evolution of municipal waste management through text-mining: A mini-review. Waste Manag. Res. 2020, 734242X20962841. [CrossRef]

32. Zupic, I.; Čater, T. Bibliometric methods in management and organization. Organ. Res. Methods 2014, 18, 429-472. [CrossRef]

33. Medina-Mijangos, R.; Seguí-Amórtegui, L. Research trends in the economic analysis of municipal solid waste management systems: A bibliometric analysis from 1980 to 2019. Sustainability 2020, 12, 8509. [CrossRef]

34. He, H.; Dyck, M.; Lv, J. The heat pulse method for soil physical measurements: A bibliometric analysis. Appl. Sci. 2020, 10, 6171. [CrossRef]

35. Cañas-Guerrero, I.; Mazarrón, F.R.; Pou-Merina, A.; Calleja-Perucho, C.; Díaz-Rubio, G. Bibliometric analysis of research activity in the "Agronomy" category from the web of science, 1997-2011. Eur. J. Agron. 2013, 50, 19-28. [CrossRef]

36. Lv, W.; Zhao, X.; Wu, P.; Lv, J.; He, H. A scientometric analysis of worldwide intercropping research based on web of science database between 1992 and 2020. Sustainability 2021, 13, 2430. [CrossRef]

37. van Eck, N.J.; Waltman, L. Software survey: VOSviewer, a computer program for bibliometric mapping. Scientometrics 2010, 84, 523-538. [CrossRef]

38. Cobo, M.J.; López-Herrera, A.G.; Herrera-Viedma, E.; Herrera, F. SciMAT: A new science mapping analysis software tool. J. Am. Soc. Inf. Sci. Technol. 2012, 63, 1609-1630. [CrossRef]

39. Persson, O.; Danell, R.; Schneider, J.W. How to use Bibexcel for various types of bibliometric analysis. Celebr. Sch. Commun. Stud. 2009, 5, 9-24.

40. van Eck, N.J.; Waltman, L. CitNetExplorer: A new software tool for analyzing and visualizing citation networks. J. Informetr. 2014, 8, 802-823. [CrossRef]

41. Chen, C. CiteSpace II: Detecting and visualizing emerging trends and transient patterns in scientific literature. J. Am. Soc. Inf. Sci. Technol. 2006, 57, 359-377. [CrossRef]

42. Zhang, D.Q.; Tan, S.K.; Gersberg, R.M. Municipal solid waste management in China: Status, problems and challenges. J. Environ. Manag. 2010, 91, 1623-1633. [CrossRef] [PubMed]

43. Wang, Y.; Long, X.; Li, L.; Wang, Q.; Ding, X.; Cai, S. Extending theory of planned behavior in household waste sorting in China: The moderating effect of knowledge, personal involvement, and moral responsibility. Environ. Dev. Sustain. 2020. [CrossRef]

44. Zhuang, Y.; Wu, S.W.; Wang, Y.L.; Wu, W.X.; Chen, Y.X. Source separation of household waste: A case study in China. Waste Manag. 2008, 28, 2022-2030. [CrossRef] [PubMed]

45. Silpa, K.; Lisa, C.Y.; Perinaz, B.-T.; Frank Van, W. What a Waste 2.0; The World Bank: Washington, WA, USA, 2018.

46. Chung, S.S.; Poon, C.S. Recycling behaviour and attitude: The case of the Hong Kong people and commercial and household wastes. Int. J. Sustain. Dev. World Ecol. 2009, 1, 130-145. [CrossRef]

47. Tonglet, M.; Phillips, P.S.; Read, A.D. Using the Theory of Planned Behaviour to investigate the determinants of recycling behaviour: A case study from Brixworth, UK. Resour. Conserv. Recycl. 2004, 41, 191-214. [CrossRef]

48. Mee, N.; Clewes, D.; Phillips, P.S.; Read, A.D. Effective implementation of a marketing communications strategy for kerbside recycling: A case study from Rushcliffe, UK. Resour. Conserv. Recycl. 2004, 42, 1-26. [CrossRef]

49. Bamberg, S.; Möser, G. Twenty years after Hines, Hungerford, and Tomera: A new meta-analysis of psycho-social determinants of pro-environmental behaviour. J. Environ. Psychol. 2007, 27, 14-25. [CrossRef]

50. Barr, S. Factors influencing environmental attitudes and behaviors. Environ. Behav. 2007, 39, 435-473. [CrossRef]

51. Tonglet, M.; Phillips, P.S.; Bates, M.P. Determining the drivers for householder pro-environmental behaviour: Waste minimisation compared to recycling. Resour. Conserv. Recycl. 2004, 42, 27-48. [CrossRef] 
52. Carrus, G.; Passafaro, P.; Bonnes, M. Emotions, habits and rational choices in ecological behaviours: The case of recycling and use of public transportation. J. Environ. Psychol. 2008, 28, 51-62. [CrossRef]

53. Gamba, R.J.; Oskamp, S. Factors influencing community residents' participation in commingled curbside recycling programs. Environ. Behav. 2016, 26, 587-612. [CrossRef]

54. Mannetti, L.; Pierro, A.; Livi, S. Recycling: Planned and self-expressive behaviour. J. Environ. Psychol. 2004, 24, 227-236. [CrossRef]

55. Tuomela, M. Biodegradation of lignin in a compost environment: A review. Bioresour. Technol. 2000, 72, 169-183. [CrossRef]

56. Quested, T.E.; Marsh, E.; Stunell, D.; Parry, A.D. Spaghetti soup: The complex world of food waste behaviours. Resour. Conserv. Recycl. 2013, 79, 43-51. [CrossRef]

57. Taylor, S.; Todd, P. An integrated model of waste management behavior. Environ. Behav. 2016, 27, 603-630. [CrossRef]

58. Kinnaman, T.C.; Fullerton, D. Garbage and recycling with endogenous local policy. J. Urban. Econ. 2000, 48, 419-442. [CrossRef]

59. Dahlen, L.; Vukicevic, S.; Meijer, J.E.; Lagerkvist, A. Comparison of different collection systems for sorted household waste in Sweden. Waste Manag. 2007, 27, 1298-1305. [CrossRef]

60. Hong, S. The effects of unit pricing system upon household solid waste management: The Korean experience. J. Environ. Manag. 1999, 57, 1-10. [CrossRef]

61. Bartelings, H.; Sterner, T. Household waste management in a swedish municipality: Determinants of waste disposal, recycling and composting. Environ. Resour. Econ. 1999, 13, 473-491. [CrossRef]

62. Knussen, C.; Yule, F.; MacKenzie, J.; Wells, M. An analysis of intentions to recycle household waste: The roles of past behaviour, perceived habit, and perceived lack of facilities. J. Environ. Psychol. 2004, 24, 237-246. [CrossRef]

63. Saphores, J.-D.M.; Nixon, H.; Ogunseitan, O.A.; Shapiro, A.A. Household willingness to recycle electronic waste. Environ. Behav. 2006, 38, 183-208. [CrossRef]

64. Chan, K. Mass communication and pro-environmental behaviour: Waste recycling in Hong Kong. J. Environ. Manag. 1998, 52, 317-325. [CrossRef]

65. Berglund, C. The assessment of households' recycling costs: The role of personal motives. Ecol. Econ. 2006, 56, 560-569. [CrossRef]

66. Ajzen, I. The theory of planned behavior. Organ. Behav. Hum. Decis. Process. 1991, 50, 179-211. [CrossRef]

67. Boldero, J. The prediction of household recycling of newspapers: The role of attitudes, intentions, and situational factors1. J. Appl. Soc. Psychol. 1995, 25, 440-462. [CrossRef]

68. Passafaro, P.; Livi, S.; Kosic, A. Local norms and the theory of planned behavior: Understanding the effects of spatial proximity on recycling intentions and self-reported behavior. Front. Psychol. 2019, 10, 744. [CrossRef]

69. Vining, J.; Ebreo, A. What makes a recycler? Environ. Behav. 2016, 22, 55-73. [CrossRef]

70. Jenkins, R.R.; Martinez, S.A.; Palmer, K.; Podolsky, M.J. The determinants of household recycling: A material-specific analysis of recycling program features and unit pricing. J. Environ. Econ. Manag. 2003, 45, 294-318. [CrossRef]

71. Fullerton, D.; Kinnaman, T.C. Household responses to pricing garbage by the bag. Am. Econ. Rev. 1996, 86, 971-984.

72. Oskamp, S.; Harrington, M.J.; Edwards, T.C.; Sherwood, D.L.; Okuda, S.M.; Swanson, D.C. Factors influencing household recycling behavior. Environ. Behav. 1991, 23, 494-519. [CrossRef]

73. Hornik, J.; Cherian, J.; Madansky, M.; Narayana, C. Determinants of recycling behavior: A synthesis of research results. J. Socio-Econ. 1995, 24, 105-127. [CrossRef]

74. Schultz, P.W.; Oskamp, S.; Mainieri, T. Who recycles and when? A review of personal and situational factors. J. Environ. Psychol. 1995, 15, 105-121. [CrossRef]

75. Garfield, E. Historiographic mapping of knowledge domains literature. J. Inf. Sci. 2016, 30, 119-145. [CrossRef]

76. Hong, S.; Adams, R.M. Household responses to price incentives for recycling: Some further evidence. Land Econ. 1999, 75, 505. [CrossRef]

77. Hage, O.; Söderholm, P.; Berglund, C. Norms and economic motivation in household recycling: Empirical evidence from Sweden. Resour. Conserv. Recycl. 2009, 53, 155-165. [CrossRef]

78. Xie, H.; Zhang, Y.; Wu, Z.; Lv, T. A bibliometric analysis on land degradation: Current status, development, and future directions. Land 2020, 9, 28. [CrossRef]

79. Rajendran, S.; Hodzic, A.; Scelsi, L.; Hayes, S.; Soutis, C.; AlMa'adeed, M.; Kahraman, R. Plastics recycling: Insights into life cycle impact assessment methods. Plast. Rubber Compos. 2013, 42, 1-10. [CrossRef]

80. Garfield, E.; Sher, I.H. KeyWords Plus ${ }^{\mathrm{TM}}$ _Algorithmic derivative indexing. J. Am. Soc. Inf. Sci. 1993, 44, 298-299. [CrossRef]

81. Zhang, J.; Yu, Q.; Zheng, F.; Long, C.; Lu, Z.; Duan, Z. Comparing keywords plus of WOS and author keywords: A case study of patient adherence research. J. Assoc. Inf. Sci. Technol. 2016, 67, 967-972. [CrossRef]

82. Mori, Y.; Kuroda, M.; Makino, N. Multiple Correspondence Analysis; Springer: Singapore, 2016; pp. 21-28. [CrossRef]

83. Cobo, M.J.; López-Herrera, A.G.; Herrera-Viedma, E.; Herrera, F. An approach for detecting, quantifying, and visualizing the evolution of a research field: A practical application to the Fuzzy Sets Theory field. J. Informetr. 2011, 5, 146-166. [CrossRef]

84. Fernández-González, J.M.; Díaz-López, C.; Martín-Pascual, J.; Zamorano, M. Recycling organic fraction of municipal solid waste: Systematic literature review and bibliometric analysis of research trends. Sustainability 2020, 12, 4798. [CrossRef]

85. Camón Luis, E.; Celma, D. Circular economy. A review and bibliometric analysis. Sustainability 2020, 12, 6381. [CrossRef]

86. Cahlik, T. Comparison of the maps of science. Scientometrics 2000, 49, 373-387. [CrossRef] 
87. Callon, M.; Courtial, J.P.; Laville, F. Co-word analysis as a tool for describing the network of interactions between basic and technological research: The case of polymer chemsitry. Scientometrics 1991, 22, 155-205. [CrossRef]

88. Soundararajan, K.; Ho, H.K.; Su, B. Sankey diagram framework for energy and exergy flows. Appl. Energy 2014, 136, 1035-1042. [CrossRef] 